\title{
Apolipoprotein E Protects against Neuropathology Induced by a High-Fat Diet and Maintains the Integrity of the Blood-Brain Barrier during Aging
}

\author{
Monique Mulder, Arjan Blokland, Dirk-Jan van den Berg, Henny Schulten, \\ Arjen H. F. Bakker, Dick Terwel, Wiel Honig, E. Ronald de Kloet, Louis M. Havekes, \\ Harry W. M. Steinbusch, and Elizabeth C. M. de Lange
}

Department of Psychiatry and Neuropsychology (MM, DT, WH, HWMS), Faculty of Medicine, Maastricht University, Maastricht; Department of Neurocognition (AB), Faculty of Psychology, and Division of Pharmacology (D-JvdB, ECMdL), Leiden University, Leiden; Department of Cardiology (HS), Faculty of Medicine, Maastricht University, Maastricht; Department of Human Biology (AHFB), Faculty of Health Sciences, and Leiden/Amsterdam Center for Drug Research (ERdK), Division of Medical Pharmacology, University of Leiden, and TNO-PG (LMH), Leiden, The Netherlands

SUMMARY: The present study provides evidence that chronic intake of a high-fat diet induces a dramatic extravasation of immunoglobulins, indicating alterations in blood-brain barrier (BBB) functioning, in the brains of apolipoprotein E (apoE)-knockout mice, but not of $\mathrm{C} 57 \mathrm{BI} / 6$ control mice. Using sodium fluorescein as a marker for the permeability of the BBB, we found additional support for age-related disturbances of BBB function in apoE-knockout mice. Behavioral analysis of apoE-knockout mice compared with $\mathrm{C} 57 \mathrm{Bl} / 6$ mice indicated that they were also less efficient in acquiring the spatial Morris water maze task. Furthermore, apoE-knockout mice are known to develop severe atherosclerosis, which is exacerbated with a high-fat diet. We therefore compared the apoE-knockout mice with the apoE3-Leiden transgenic mice, which are known to develop atherosclerosis. However, apoE3-Leiden mice that were kept on a high-fat, high-cholesterol diet and that developed atherosclerosis to an extent similar to the apoE-knockout mice, showed no signs of BBB disturbances. These results indicate for the first time that apoE plays an essential role in the maintenance of the integrity of the BBB during aging and that it protects the brain from neuropathology induced by a high-fat diet. We therefore hypothesize that the role of apoE in the maintenance of the integrity of the BBB may be the mechanism by which apoE affects the progression of neurodegeneration, as seen in Alzheimer's disease. (Lab Invest 2001, 81:953-960).

\begin{abstract}
A polipoprotein $E$ (apoE) is synthesized in almost all cell types and throughout the body. Within the brain, astrocytes are the predominant source of apoE (Pitas et al, 1987). It is thought that apoE functions by mediating neuronal repair and/or remodeling during development and during regeneration after injury to the central nervous system by mediating the distribution of lipids, predominantly cholesterol and phospholipids (Nathan et al, 1994).

Three common human isoforms of apoE exist: E2, $\mathrm{E} 3$, and E4. ApoE4 is now a well-established risk factor for the development of Alzheimer's disease (AD) (Corder et al, 1993; Saunders et al, 1993). ApoE4 has also been associated with other neurological dis-
\end{abstract}

\section{Received January 22, 2001.}

This study was supported in part by grants from the Internationale Stichting Alzheimer Onderzoek (ISAO, Grant 98505) and the Hersenstichting Nederland (Grant H0O.15).

Address reprint requests to: Dr. Monique Mulder, Maastricht University, Department of Psychiatry and Neuropsychology, Universiteitssingel 50, P.O. Box 616, 6200 MD Maastricht, The Netherlands. E-mail: M.Mulder@NP.unimaas.nl eases, including vascular dementia and a poor clinical outcome in patients after stroke and head injury (Nicoll et al, 1995; Slooter et al, 1997). The mechanism by which apoE4 affects the process of neurodegeneration, however, is largely unknown.

Mice deficient in apoE display disturbances in learning and memory function as well as in long-term potentiation (Krugers et al, 1997; Krzywkowski et al, 1999; Oitzl et al, 1997; Veinbergs and Masliah, 1999). They display several neuropathologic alterations, including a loss of synapses with increasing age, cytoskeletal alterations (Masliah et al, 1995), and a reduced activity of choline acetyltransferase (Gordon et al, 1995). In addition, they show an impaired response to ischemic, traumatic, and excitotoxic lesions (Chen et al, 1997; Laskowitz et al, 1997). On the contrary, a few studies report neither significant alterations in behavior nor any neuropathology in apoEknockout mice (Anderson et al, 1999; Krzywkowski et al, 1999).

ApoE has long been known as a key regulator of plasma lipid levels and its absence results in the development of atherosclerosis (Plump et al, 1992; 
van Ree et al, 1995). ApoE-knockout mice develop xanthomata including cerebral xanthomata (van Ree et al, 1995). They have also been found to display a brain region-specific extravasation of foamy macrophages (Mato et al, 1999) and an accumulation of markers of lipid peroxidation (Montine et al, 1999; Pratico et al, 1999). A high-fat diet accelerates the progression of atherosclerosis (Plump et al, 1992) and induces the development of xanthomatous lesions in the brain that consist of crystalline cholesterol clefts, lipid globules, and foam cells (Mato et al, 1999; Walker et al, 1997). This indicates that disorders in lipid metabolism may finally result in pathological changes in the central nervous system.

Here we present experimental evidence that apoE protects against neuropathology induced by a high-fat diet. We show that this protective effect of apoE is independent of the protective effect of apoE against atherosclerosis. These results suggest that the protective effect of apoE is due to its role in the maintenance of the integrity of the blood-brain barrier (BBB) during aging.

\section{Results}

The brains of male apoE-knockout and C57Bl/6 control mice that were fed a high-fat Western-type diet (16\% fat, $2 \%$ choline, and $0.25 \%$ cholesterol) for a period of 10 months were examined for neuropathology. Macroscopically we observed shrinkage of the brains of apoE-knockout mice, but not of the control mice (data not shown). Unexpectedly, we found a strong immunoreactivity for immunoglobulin gamma (IgG) throughout the brains of apoE-knockout mice, indicating alterations in BBB functioning (SchmidtKastner et al, 1993). No IgG-immunoreactivity was detected in the brains of control C57BI/6 mice. Figure 1 shows IgG immunoreactivity within the hippocampal formation (Fig. 1a), as well as in the cerebellum (Fig. 1, C and d), of apoE-knockout mice and C57BI/6 control mice (Fig. 1, b, e, and f). In the molecular layer of the cerebellum of apoE-knockout mice, glial cells also displayed strong lgG immunoreactivity (Fig. 1c). These glial cells appear to be microglial cells because they did not counterstain for glial fibrillary acidic protein (not shown).

We determined whether the extravasation of IgG is induced by the chronic consumption of a high-fat diet or by the absence of apoE. For this purpose male apoE-knockout mice and $\mathrm{C} 57 \mathrm{BI} / 6$ control mice were fed a standard chow diet and compared with apoEknockout mice fed a high-fat, high-cholesterol diet for a period of 3 months, starting at age 8 months. Because conflicting results have been reported with respect to alterations in the behavior of apoEknockout mice (Krugers et al, 1997; Krzywkowski et al, 1999; Oitzl et al, 1997; Veinbergs and Masliah, 1999), the apoE-knockout mice and the C57BI/6 control mice were compared with respect to their behavioral performance in the Morris water maze task. ApoEknockout mice fed a high-fat, high-cholesterol diet were eventually excluded from behavioral experiments because they developed xanthomata that impaired
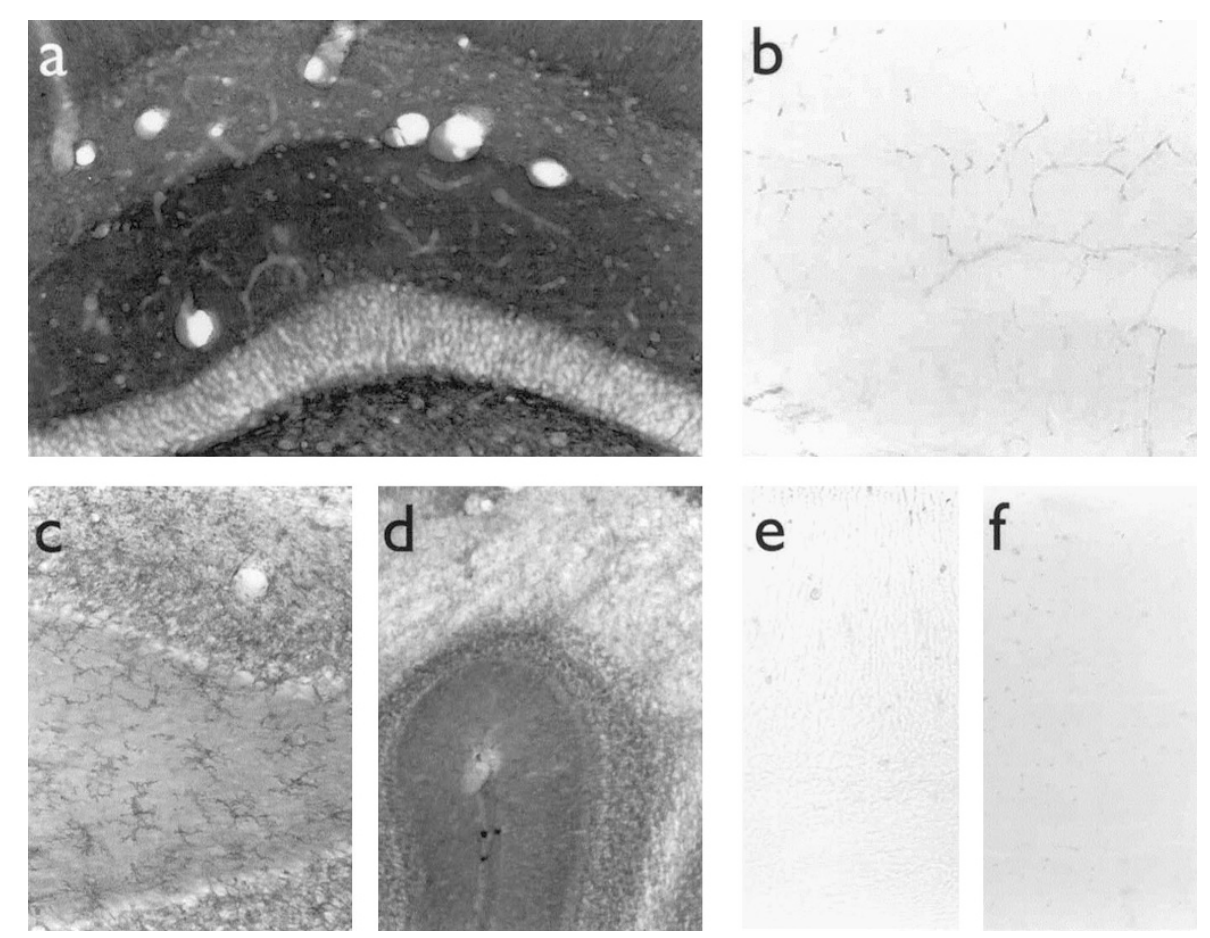

Figure 1.

Eleven-month-old apolipoprotein E (apoE)-knockout mice $(n=5)$ and C57BI/6 control mice $(n=5)$ that had been fed a high-fat Western-type diet for 10 months were compared with respect to IgG staining. Hippocampus (a) and cerebellum (c and d) of apoE-knockout mice. Hippocampus (b) and cerebellum (e and f) of control mice (original magnification, $\times 200$ ). IgG staining increased dramatically in all five of the apoE-knockout mice and in none of the control mice examined. 
their swimming ability. During the trials with a visible platform, which preceded training with a hidden platform, the path length to reach the platform was much shorter and the swimming speed was lower for the apoE-knockout mice than for the control mice $(\mathrm{t}[11]=$ 2.75, $p<0.05$, Fig. $2 a$, and $\mathrm{t}[11]=4.79, p<0.01$, Fig. $2 \mathrm{~d}$, respectively). Both groups of mice showed a similar performance during the first four trials with a hidden platform and learned the task to a similar degree. However, when the first four blocks were analyzed, a trend was found for a retarded rate of learning (blocks $\times$ group) as measured by the distance moved $(F[3,33]=2.84, p<0.07$, Fig. 2a) and the time to platform $(F[3,33]=2.87, p<0.06$, Fig. $2 b)$. This retarded acquisition was clearly found for the parameter average distance to platform $(F[3,33]=3.14, p<$ 0.05 , Fig. 2c). There were no differences in swimming speed during training. During the probe trial, when the platform was removed, both the control mice and the ApoE-knockout mice spent $50 \%$ of the time in the quadrant in which the platform was located during acquisition. There were no differences in swimming speed or the average distance to the (fictitious) platform (not shown).

After the behavioral study, some of the mice $(n=4)$ were killed and the brains were stained for IgG. An increase in IgG staining, indicating disturbances of the BBB (Schmidt-Kastner et al, 1993), was found in the brains of apoE-knockout mice, but not in brains of control mice; staining was located predominantly in the hippocampal regions CA1 and dentate gyrus (Fig. 3 , $a$ and $c$ ). The IgG staining in the brains of apoE-
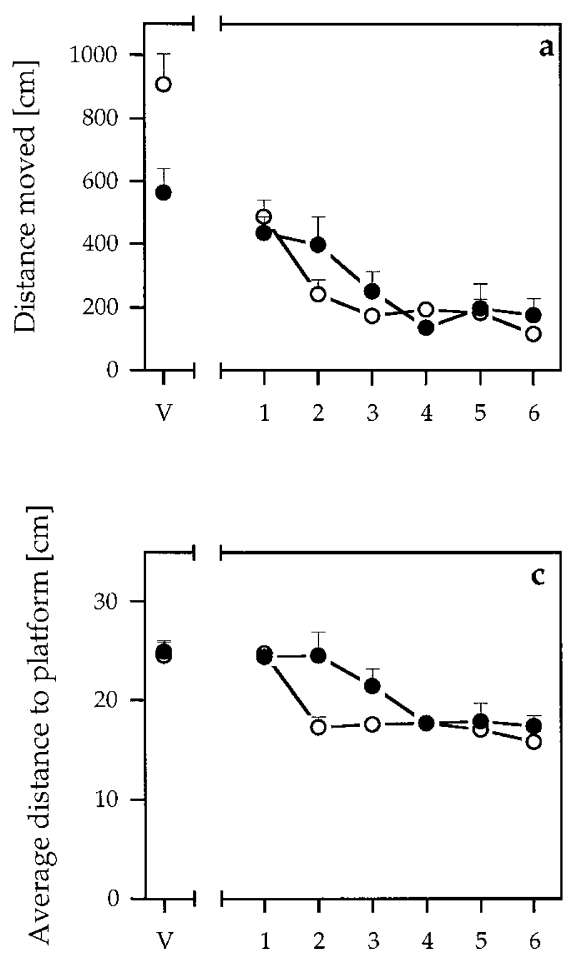

knockout mice was enhanced as a result of the intake of a high-fat, high-cholesterol diet for a period of 3 months (Fig. 3, b and d), but to a lesser extent than in the apoE-knockout mice fed a high-fat diet for 10 months. IgG levels in serum of apoE-knockout mice fed a chow diet did not differ significantly from those in apoE-knockout mice fed a high-fat, high-cholesterol $\operatorname{diet}(13.0 \pm 7.3$ vs $12.0 \pm 6.1)$.

BBB integrity was also determined by transport of the hydrophilic molecule sodium fluorescein (Flu) in the brain of the mice, after the behavioral study, that were not stained for IgG. BBB transport of Flu was determined using the ratio of brain to plasma concentrations. The tendency toward an increased brain to plasma ratio of Flu in 11-month-old male apoEknockout mice compared with $\mathrm{C} 57 \mathrm{BI} / 6$ mice $(9.7 \pm$ $3.2 \%[n=5]$ vs $5.4 \pm 2.8 \%[n=4]$, respectively; $p<$ 0.07 ) supports a disrupted BBB. Subsequently in a separate experiment, a comparable increase in the brain to plasma ratio of Flu was observed in female apoE-knockout mice compared with female wildtype mice $(5.4 \pm 1.6 \%[n=6]$ vs $3.3 \pm 1.8 \%[n=6] ; p<$ 0.06).

ApoE-knockout mice are also known to accumulate high levels of cholesterol in plasma, which leads to severe atherosclerotic lesions in the vessels, particularly after high-fat feeding (Plump et al, 1992). The development of atherosclerotic lesions starts by the age of 2.5 months and becomes more severe by the age of 5 to 6 months. Therefore, disturbances in the integrity of the BBB as observed in the apoE-knockout mice may be due to the absence of apoE per se or
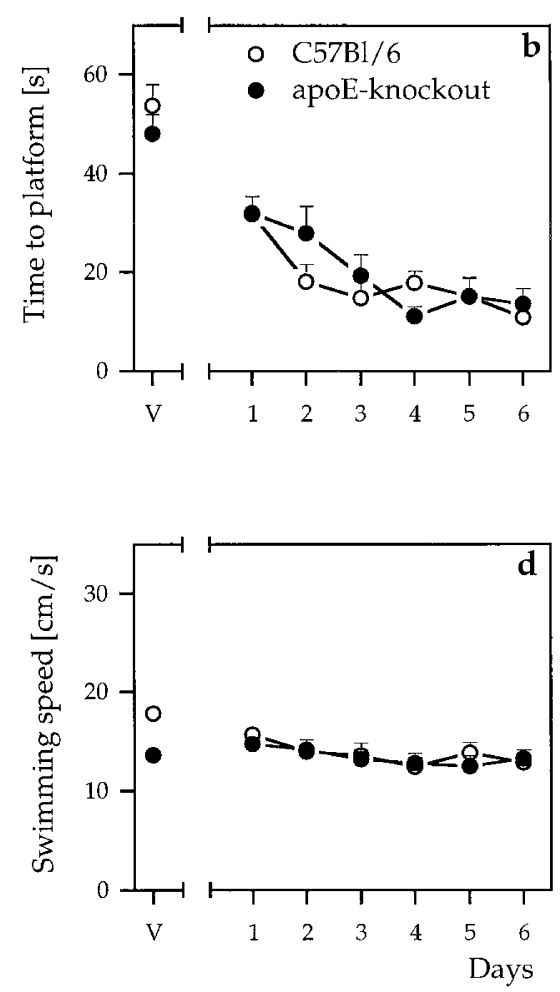

Figure 2.

Performance in the Morris water maze of 11-month-old apoE-knockout mice and C57BI/6 control mice. a, Distance moved; b, time to platform; c, average distance to platform; and d, swimming speed. Data represent mean \pm SEM. 

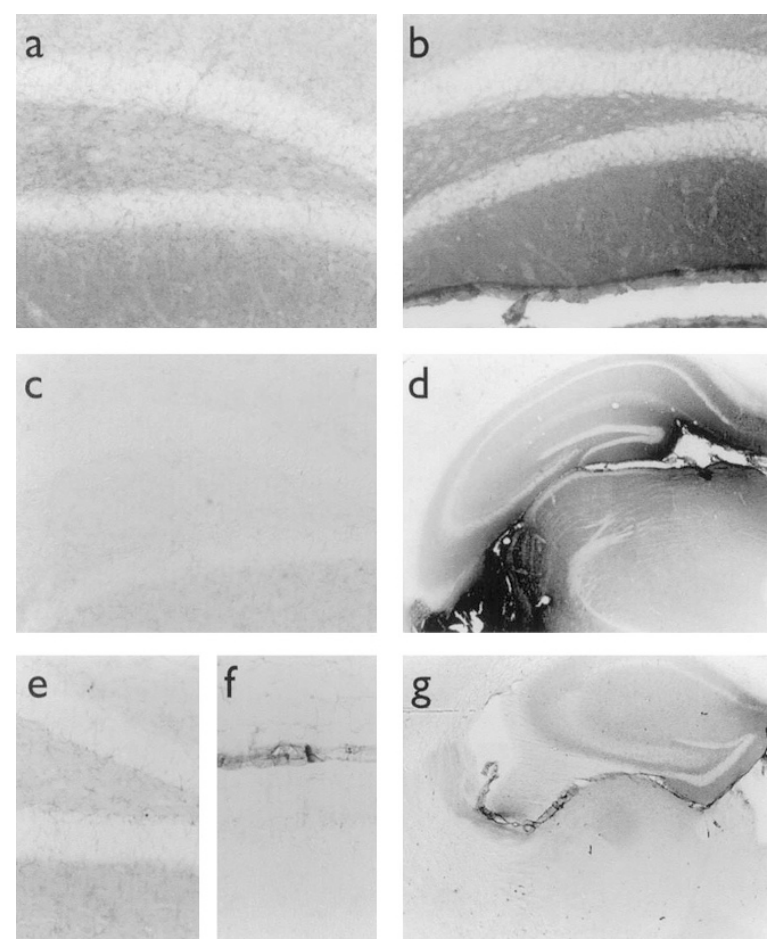

Figure 3.

Immunostaining for IgG of the dentate gyrus hippocampal region. a, ApoEknockout mouse on a standard chow diet (original magnification, $\times 200$ ). b and d, ApoE-knockout mice on a high-fat, high-cholesterol diet for 3 months (original magnification, $\times 200$ and $\times 40$, respectively). c, C57BI/6 control mouse on a standard chow diet (original magnification, $\times 200$ ). e, Dentate gyrus, f, cerebellum (original magnification, $\times 200$ ), and $g$, hippocampus (original magnification, $\times 40$ ) of apoE3-Leiden transgenic mice on a high-fat, high-cholesterol diet for 9 to 10 months. ApoE-knockout mice and C57BI6 mice are 11-month-old males, and apoE3-Leiden mice are females of the same age. The IgG staining in the apoE3-Leiden mice is not noticeably increased when compared with the controls, whereas staining is increased in the apoE-knockout mice and increases further after intake of a high-fat, highcholesterol diet.

may be secondary to factors related to hypercholesterolemia and atherosclerosis. No differences were found in either IgG staining or in the brain/plasma ratio of Flu in 3-month-old apoE-knockout and control mice $(2.4 \pm 0.9 \%[n=5]$ vs $1.9 \pm 0.7 \%[n=7]$, respectively; $p>0.1$ ). This indicates that BBB integrity alterations occur in older animals.

To investigate if disturbances in BBB integrity are secondary to the development of atherosclerosis, another model for hypercholesterolemia and atherosclerosis, the apoE3-Leiden transgenic mouse, was used (Van den Maagdenberg et al, 1993). When fed a severely high-fat, high-cholesterol diet, apoE3-Leiden mice can display serum cholesterol levels that are comparable to those in apoE-knockout mice (Gijbels et al, 1999). We found that the brains of 11-month-old female apoE3-Leiden mice fed a severely high-fat, high-cholesterol diet for 9 months did not show a noticeable increase in IgG staining as observed in the apoE-knockout mice with elevated cholesterol levels (53 \pm 5.5 vs $28 \pm 10 \mathrm{mmol} / \mathrm{l}$ in apoE3-Leiden and apoE-knockout mice, respectively; Fig. 3, e to g), with the exception of some IgG-positive glial cells, most likely microglial, in the hippocampus and cerebellum.
This indicates that in the presence of apoE, high plasma cholesterol levels and the development of atherosclerosis does not lead to extravasation of IgG in the brain.

\section{Discussion}

The absence of apoE in mice directly leads to an increased susceptibility to neuropathology induced by a high-fat diet; that is, shrinkage of the brain and a dramatic extravasation of IgGs in the brain. Furthermore, the absence of apoE induces age-related alterations in the integrity of the BBB, as indicated by the presence of lgGs in the brain and an increase in the brain to plasma ratio of Flu. Disturbances in BBB integrity were found to parallel a poorer performance in the Morris water maze task. Furthermore, we show that the neuropathology induced by a high-fat diet is not due to the increased plasma cholesterol levels caused by the absence of apoE.

The BBB is a complex structure essential for maintaining central nervous system homeostasis. The BBB consists mainly of vascular endothelia surrounded by a layer of astrocytes (Pardridge, 1991). Within the brain, astrocytes are the predominant source of apoE (Pitas et al, 1987). BBB permeability is known to be increased in a number of central nervous system pathologies, particularly those with inflammatory components. Until now little has been known about the mechanism of increased BBB permeability. Alterations in the integrity of the BBB may contribute to processes of neurodegeneration via the dysregulation of brain immunity, impairing transport of crucial nutrients, decreasing the disposal of waste products, and/or by allowing the entrance of toxic agents into the brain. Because immune activation in the brain can specifically disrupt cognitive processes involved in learning and memory in experimental animal models as well as in humans, it has been hypothesized that cognitive deficits in AD are a consequence of central nervous system inflammatory processes (Gahtan and Overmier, 1999).

Conflicting results have been reported in the literature about the performance of apoE-knockout mice in the Morris water maze task (Anderson et al, 1999; Gordon et al, 1995; Oitzl et al, 1997; Veinbergs and Masliah, 1999). It is thought that the differing results may be caused by differences in mouse strain or genetic background, housing conditions, life events, or nutrition (Lominska et al, 2001; Veinbergs and Masliah, 1999). We therefore subjected the mice to the Morris maze task and subsequently examined the integrity of the BBB. Changes in BBB integrity were indicated by the presence of IgG in the brain, which is regarded as a very strong indication of BBB disruption (Schmidt-Kastner et al, 1993), and by an increase in the brain/plasma ratio of Flu after intravenous administration of Flu. Our results show that in male apoEknockout mice, disruption of the BBB paralleled a poorer performance in the Morris maze task. It can be speculated that the absence of apoE indirectly affects 
the BBB through a modulatory effect of apoE on the immune system. ApoE-knockout mice were found to display an altered immune response (Laskowitz et al, 2000). In addition, with the progression of atherosclerosis, the titers of autoantibodies to various oxidationspecific neoepitopes of oxidized low density lipoprotein in plasma increase (Palinski et al, 1996). It has also been found that infection with retroviruses induces disruption of the BBB in mice (Kustova et al, 1999). In addition, evidence is accumulating to indicate that vascular factors, including BBB disturbances, play an important role in the progression of several neurodegenerative diseases including AD. It has been suggested that apoE4 increases the risk for $A D$ because of its association with vascular modifications, that is, atherosclerosis and hypertension (Mulder and Terwel, 1998). Recently atherosclerosis was excluded as an intermediary in the association between APOE genotype and dementia (Slooter et al, 1999). However, a strong association of apoE4 with the vascular deposition of $\beta$-amyloid in cerebral blood vessels has been reported by several groups (Greenberg et al, 1995; Premkumar et al, 1996; Schmechel et al, 1993).

Another possibility is that apoE synthesized at the site of the BBB directly plays an important role in maintaining the integrity of the BBB. It has been reported that aged apoE-knockout mice, similar to patients with $A D$, display increased levels of lipid peroxidation products in their plasma and brains compared with age-matched wildtype mice (Pratico et al, 1999). In another mouse model for atherosclerosis, the low density lipoprotein receptor knockout mouse, when fed a high-fat diet (Pratico et al, 1999), had increased levels of peroxidation products are found in plasma but not in the brain (Pratico et al, 1999; Tangirala et al, 2001). This may indicate age-related changes in the occurrence of lipid peroxidation products in the brain in the absence of apoE, which may then be related to the antioxidant role of apoE (Miyata and Smith, 1996). However, increased levels of peroxidation products in the brains of apoE-knockout mice but not in low density lipoprotein receptor knockout mice may also indicate age-related disruption of the BBB in apoE-knockout mice that allows the passage of lipid peroxidation products.

Our results lead to a new hypothesis concerning the mechanism by which apoE affects the process of neurodegeneration. The present study indicates that apoE is necessary for the maintenance of the integrity of the BBB during aging and that the absence of apoE renders the mice vulnerable to high-fat-induced neurodegeneration. It can be speculated that the alterations in BBB integrity underlie the age-related neuropathological and behavioral alterations observed in apoE-knockout mice (Masliah et al, 1995; Veinbergs and Masliah, 1999). It remains to be established exactly how BBB disturbances affect the behavior of apoE-knockout mice. Furthermore, BBB alterations may also underlie the increased susceptibility of apoEknockout mice to injury of the central nervous system (Chen et al, 1997; Laskowitz et al, 1997; Masliah et al, 1995; Veinbergs and Masliah, 1999).
Based on these facts and the results of our studies, it can be hypothesized that apoE-genotype-specific differences in maintaining the integrity of the BBB with aging may be the mechanism by which apoE affects the progression of $A D$. Our results indicate that nutritional factors may contribute to the process of neurodegeneration in genetically predisposed subjects. It can be hypothesized that apoE4 is less efficient than apoE3 or apoE2 in maintaining BBB integrity and thereby lowers the threshold for the development of AD. This hypothesis is presently under investigation. During the progression of $A D$, alterations in the integrity of the BBB may act synergistically with other pathogenic mechanisms, including genetic and environmental factors such as diet. The protective role of apoE in diet-induced BBB dysfunction could be an interesting therapeutic target.

\section{Materials and Methods}

\section{Animals}

ApoE-knockout mice (van Ree mouse line, van Ree et al, 1995) and transgenic mice expressing human APOE3-Leiden and APOC1 genes (line 2) generated by conventional transgenesis as described earlier (Van den Maagdenberg et al, 1993) were obtained from TNO-PG in Leiden (Prof. Dr. L. M. Havekes). C57BI6 and apoE-knockout mice (Breslow mouse line) were obtained from Charles River, Someren, The Netherlands.

The mice were fed either a standard chow diet or one of the following high-fat diets: a Western-type diet (10\% butter, $0 \%$ cholate, and $0.25 \%$ cholesterol) for 9 to 10 months, starting at week 6 (male C57Bl6 and apoE-knockout mice); a high-fat, high-cholesterol diet ( $19 \%$ butter, $0.5 \%$ cholate, and $1.25 \%$ cholesterol) for 3 months, starting at 8 months (male apoE-knockout mice); or a high-fat, high-cholesterol diet (15\% butter, $0.5 \%$ cholate, and $1 \%$ cholesterol) for 9 months, starting at week 6 (female apoE3-Leiden transgenic mice).

\section{Behavioral Experiments}

Morris Water Maze Task. Three days before the beginning of the behavioral testing, the mice were housed individually. The spatial discrimination performance of mice was assessed in a circular black water tank (diameter $79 \mathrm{~cm}$, depth $27 \mathrm{~cm}$ ) filled with clear tap water $\left(20\right.$ to $\left.22^{\circ} \mathrm{C}\right)$. First the mice were given two trials in which a white platform (diameter $8 \mathrm{~cm}$ ) was visible. The location of this platform was different for both trials. Subsequently, the mice were given a total of 24 trials (four trials a day) in which a grey platform was submerged. During training the platform remained at a fixed position. Trials were ended after a mouse had found and climbed onto the platform. The mouse was left for 3 seconds, after which it was allowed to climb onto a sieve and was put back into its cage. In each trial the place where the mouse was put in the water differed (four starting positions). If the mouse could 
not find the platform within 60 seconds, it was guided there with a sieve, and after 3 seconds on the platform was put back into its cage. After the fourth trial on day 6, a "probe" trial was given to reveal memory effects and the strategies followed. For this purpose the platform was removed from the water tank and the behavior of the mice was registered (3 samples/ second) using a video tracking system (EthoVision; Noldus Information Technology, Wageningen, The Netherlands) and stored on a computer. The parameters for the analysis of spatial discrimination and learning were as follows: distance moved (the length of the path swum from the starting position to the platform), time to platform (the time needed to find the platform), average distance to platform (the sum of the distance to platform for each sample point divided by the number of sample points; estimate of the distance to the platform during a swim trial), and swimming speed (the mean speed of swimming during a trial). For the analysis of the probe trial, the time the mice swam in the different quadrants was evaluated. Group differences on the visual trials were analyzed with a $t$ test. The data obtained were analyzed using an analysis of variance with the factor blocks as repeated measurements.

\section{BBB Integrity}

Flu Marker. Flu was injected into the tail vein in unanesthetized 11-month-old male apoE-knockout or C57Bl6 mice (50 $\mu \mathrm{l} / 30 \mathrm{~g}$ body weight of $20 \mathrm{mg} / \mathrm{ml} \mathrm{Flu})$. A similar, but separate, experiment was performed with female apoE-knockout and wildtype mice. After 90 minutes the mice were decapitated, brains were removed and immediately frozen in liquid nitrogen. Blood was collected in heparinized tubes and centrifuged to obtain plasma. Flu was analyzed using a high performance liquid chromatography (HPLC) system, HEMA SEC BIO 300 column $(10 \mu \mathrm{M}, 25 \mathrm{~cm}, 4.6 \mathrm{~mm}$ inside diameter; Allech, Capelle aan den IJssel, The Netherlands), and a fluorescence detector (LC 240; Perkin Elmer Cetus, Norwalk, Connecticut) set at an excitation and emission wavelength of 498 and 525 $\mathrm{nm}$, respectively. The mobile phase was a mixture of $75 \mathrm{~mm}$ of $\mathrm{Na}_{2} \mathrm{HPO}_{4}, \mathrm{pH}=9$, and $10 \%$ methanol (v/v). The flow rate was $0.75 \mathrm{~m} / \mathrm{minute}$, at $30^{\circ} \mathrm{C}$. Chromatographic data were recorded and processed with a SP4100 computing integrator (Spectra Physics BV, Eindhoven, The Netherlands).

\section{Immunohistochemistry}

Eleven-month-old mice were anesthetized with Nembutal $(50 \mathrm{mg} / \mathrm{kg})$ and transcardially perfused under low pressure with PBS $\left(10 \mathrm{ml}, 4^{\circ} \mathrm{C}\right)$, followed by $100 \mathrm{ml}$ of fixative $(4 \%$ paraformaldehyde in $0.1 \mathrm{M}$ phosphate buffer, $\mathrm{pH}$ 7.4). The brain and liver were removed and postfixed overnight in the same fixative at $4^{\circ} \mathrm{C}$. Subsequently the brains were transferred to $0.1 \mathrm{M}$ PBS containing $30 \%$ sucrose, frozen, and cut into $35-\mu \mathrm{m}-$ thick sections with a cryostat. Cryostat sections were stored at $-80^{\circ} \mathrm{C}$. Eleven-month-old apoE-knockout mice and wildtype mice that had been fed a Westerntype diet and the apoE3-Leiden transgenic mice were anesthetized with Nembutal $(50 \mathrm{mg} / \mathrm{kg})$ and perfused under low pressure with Tyrode buffer $\left(10 \mathrm{ml}, 4^{\circ} \mathrm{C}\right)$, followed by $100 \mathrm{ml}$ of Somogyi fixative $\left(4^{\circ} \mathrm{C}\right)$. The brains were postfixed in the same fixative overnight and subsequently stored in Millonigs at $4^{\circ} \mathrm{C}$. Brains were sliced using a vibratome. All of the animal experiments were approved by the animal ethical committee at Maastricht University.

Vibratome sections of $35 \mu \mathrm{m}$ were incubated overnight with rabbit-anti-apoE (1:20,000, kindly provided by Dr. N. Pearce, Smith Kline Beecham, London, United Kingdom) after they had been rinsed in Trisbuffered saline containing $0.1 \%$ Triton- $\times 100$ (TBS-t), TBS, and TBS-t, respectively. After overnight incubation, the slices were rinsed as described and incubated with a second antibody (biotin-labeled donkeyanti-rabbit 1:800; Jackson/Immunoresearch, West Grove, Pennsylvania) and subsequently with avidin:biotinylated enzyme complex (Elite ABC kit; Vector Laboratories, Burlingame, California) for 2 hours. Diaminobenzidine was used to reveal the binding of the apoE antibody. IgG were localized using biotin-labeled donkey-anti-mouse IgG (Jackson/Immunoresearch) and subsequently with avidin:biotinylated enzyme complex. IgG staining of the brains of the apoEknockout mice fed a high-fat diet was confirmed using horse-anti-mouse $\operatorname{lgG} / \mathrm{lgM}$ and was not observed when biotin-labeled donkey-anti-rabbit antibodies were used in combination with the avidin:biotinylated enzyme complex.

\section{Acknowledgements}

We are grateful to Dr. K. Willems-van Dijk for providing the apoE-knockout mice and to Miss C. Vuijst, Mr. E. Palsen, and Miss N. Bitch for their excellent technical assistance.

\section{References}

Anderson R, Barnes JC, Bliss TV, Cain DP, Cambon K, Davies HA, Errington ML, Fellows LA, Gray RA, Hoh T, Stewart M, Large CH, and Higgins GA (1999). Behavioural, physiological and morphological analysis of a line of apolipoprotein E knockout mouse. Neuroscience 85:93-110.

Chen Y, Lomnitski L, Michaelson DM, and Shohami E (1997). Motor and cognitive deficits in apolipoprotein $E$ deficient mice after closed head injury. Neuroscience 80:1255-1262.

Corder EH, Saunders AM, Strittmatter WJ, Schmechel DE, Gaskell PC, Small GW, Rose AD, Haines JL, and PericakVance MA (1993). Gene dose of apolipoprotein E type 4 allele and the risk of Alzheimer's disease in late onset families. Science 261:921-923.

Gahtan E and Overmier JB (1999). Inflammatory pathogenesis in Alzheimer's disease: Biological mechanisms and cognitive sequeli. Neurosci Biobehav Rev 23:615-633.

Gijbels MJJ, van der Cammen M, van der Laan LJ, Emeis JJ, Havekes LM, Hofker MH, and Kraal G (1999). Progression and regression of atheroslcerosis in APOE3-Leiden transgenic mice: An immunohistochemical study. Atherosclerosis 143:15-25. 
Gordon I, Grauer E, Genis I, Sehayek E, and Michaelson DM (1995). Memory deficits and cholinergic impairments in apolipoprotein E-deficient mice. Neuroscience 199:1-4.

Greenberg SM, Rebeck GW, Vonsattel JP, Gomez-Isla T, and Human BT (1995). Apolipoprotein E $\epsilon 4$ and cerebral hemorrhage associated with amyloid angiopathy. Ann Neurol 38: 254-259.

Krugers HJ, Mulder M, Korf J, Havekes L, de Kloet ER, Joגls M (1997). Altered synaptic plasticity in hippocampal CA1 area of apolipoprotein E deficient mice. NeuroReport 8:25052510.

Krzywkowski P, Ghribi O, Gagne J, Chabot C, Kar S, Rochford J, Massicotte G, and Poirier J (1999). Cholinergic systems and long-term potentiation in memory-impaired apolipoprotein E-deficient mice. Neuroscience 92:1273-1286.

Kustova Y, Grinberg A, Basile AS (1999). Increased bloodbrain barrier permeability in LP-BM5 infected mice is mediated by neuroexcitatory mechanisms. Brain Res 839:153163.

Laskowitz DT, Lee DM, Schmechel D, and Staats HF (2000). Altered immune responses in apolipoprotein E-deficient mice. J Lipid Res 41:613-620.

Laskowitz DT, Sheng H, Bart RD, Joyner KA, Roses AD, and Warner DS (1997). Apolipoprotein E-deficient mice have increased susceptibility to focal cerebral ischemia. J Cereb Blood Flow Metab 17:753-758.

Lominska C, Levin JA, Wang J, Sikes J, Kao C, and Smith JD (2001). Apolipoprotein $E$ deficiency effects on learning in mice are dependent upon the background strain. Behav Brain Res 120:23-34.

Masliah E, Mallory M, Ge N, Alford M, Veinbergs I, and Roses AD (1995). Neurodegeneration in the central nervous system of apoE-deficient mice. Exp Neurol 136:107-122.

Mato M, Ookawara S, Mashiko T, Sakamoto A, Mato TK, Maeda N, and Kodama T (1999). Regional difference of lipid distribution in brain of apolipoprotein $\mathrm{E}$ deficient mice. Anat Rec 256:165-176.

Miyata M and Smith JD (1996). Apolipoprotein E allelespecific antioxidant activity and effects on cytotoxicity by oxidative insults and beta-amyloid peptides. Nat Genet 14: 55-61.

Montine TJ, Montine KS, Olson SJ, Graham DG, Roberts LJ, Morrow JD, Linton MF, Fazio S, and Swift LL (1999). Increased cerebral cortical lipid peroxidation and abnormal phospholipids in aged homozygous apoE-deficient C57BL/6J mice. Exp Neurol 158:234-241.

Mulder M and Terwel D (1998). Possible link between lipid metabolism and cerebral amyloid angiopathy in Alzheimer's disease: A role for high-density lipoproteins? Haemostasis 28:174-194.

Nathan BP, Bellosta S, Sanan DA, Weisgraber KH, Mahley RW, and Pitas E (1994). Differential effects of apolipoproteins E3 and E4 on neuronal growth in vitro. Science 264:850-852.

Nicoll JA, Roberts G, and Graham DI (1995). Apolipoprotein E epsilon 4 allele is associated with deposition of amyloid beta-protein following head injury. Nat Med 1:135-137.

Oitzl MS, Mulder M, Lucassen PJ, Havekes LM, Grootendorst J, and de Kloet ER (1997). Severe learning deficits in apolipoprotein E-knockout mice in a water maze task. Brain Res 752:189-196.
Palinski W, Horkko S, Miller EM, Steinbrecher UP, Powell HC, Curtiss LK, and Witztum JL (1996). Cloning of monoclonal autoantibodies to epitopes of oxidized lipoproteins from apolipoprotein E-deficient mice: Demonstration of epitopes of oxidized low density lipoprotein in human plasma. J Clin Invest 98:800-814.

Pardridge WM (1991). Advances in cell biology of blood-brain barrier transport. Semin Cell Biol 2:419-422.

Pitas RE, Boyles JK, Lee SH, and Weisgraber KH (1987). Lipoproteins and their receptors in the central nervous system: Characterization of the lipoproteins in cerebrospinal fluid and identification of apolipoprotein $B, E(L D L)$ receptors in the brain. J Biol Chem 262:14352-14360.

Plump AS, Smith JD, Hayek T, Aalto-Setala K, Walsh A, Verstuyft JG, Rubin EM, and Breslow JL (1992). Severe hypercholesterolemia and atherosclerosis in apolipoprotein E-deficient mice created by homologous recombination in ES cells. Cell 71:343-353.

Pratico D, Rokach J, and Tangirala RK (1999). Brains of aged apolipoprotein E-deficient mice have increased levels of F2-isoprostanes, in vivo markers of lipid peroxidation. J Neurochem 73:736-741.

Premkumar DR, Cohen DL, Hedera P, Friedland RP, and Kalaria RN (1996). Apolipoprotein E- $\epsilon 4$ alleles in cerebral amyloid angiopathy and cerebrovascular pathology associated with Alzheimer's disease. Am J Pathol 148:2083-2095.

Saunders AM, Strittmatter WJ, Schmechel D, George-Hyslop PH, Pericak-Vance MA, Joo SH, Rosi BL, Gusella JF, Crapper-MacLachlan DR, and Alberts MJ (1993). Association of apolipoprotein E allele E4 with late-onset familial and sporadic Alzheimer's disease. Neurology 43:1467-1472.

Schmechel DE, Saunders AM, Strittmatter WJ, Crain BJ, Hulette CM, Joo SH, Pericak-Vance MA, Goldgaber D, and Roses AD (1993). Increased amyloid beta-peptide deposition in cerebral cortex as a consequence of apolipoprotein $E$ genotype in late-onset Alzheimer disease. Proc Natl Acad Sci USA 90:9649-9647.

Schmidt-Kastner R, Meller D, Bellander BM, Stromberg I, Olson L, and Ingvar M (1993). A one-step immunohistochemical method for detection of blood-brain barrier disturbances for immunoglobulins in lesioned rat brain with special reference to false-positive staining in immunohistochemistry. J Neurosci Methods 46:121-132.

Slooter AJ, Cruts M, Ott A, Bots ML, Witteman JC, Hofman A, Van Broeckhoven C, Breteler MM, and van Duijn CM (1999). The effect of APOE on dementia is not through atherosclerosis: The Rotterdam Study. Neurology 53:15931595.

Slooter AJ, Tang MX, van Duijn CM, Stern Y, Ott A, Bell K, Breteler MM, Van Broeckhoven C, Tatemichi TK, Tycko B, Hofman A, and Mayeux R (1997). Apolipoprotein E $\epsilon 4$ and the risk of dementia with stroke: A population-based investigation. JAMA 277:818-821.

Tangirala RK, Pratico D, FitzGerald GA, Chun S, Tsukamoto K, Maugeais C, Usher D, Pure E, and Rader DJ (2001). Reduction of isoprostanes and regression of advanced atherosclerosis by apolipoprotein E. J Biol Chem 276:261-266.

Van den Maagdenberg AMJM, Hofker MH, Krimpenfort PJ, Bruijn I, van Vlijmen, B, van der Boom H, Havekes LM, and Frants RR (1993). Transgenic mice carrying the apolipoprotein E3-Leiden gene exhibit hyperlipoproteinemia. J Biol Chem 268:10540-10545. 
van Ree JH, Gijbels MJ, van den Broek WJ, Hofker MH, and Havekes LM (1995). Atypical xanthomatosis in apolipoprotein E-deficient mice after cholesterol feeding. Atheroslerosis 112:237-243.

Veinbergs I and Masliah E (1999). Synaptic alterations in apolipoprotein E knockout mice. Neuroscience 91:401-403.
Walker LC, Parker CA, Lipinski WJ, Callahan MJ, Carroll RT, Gandy SE, Smith JG, Jucker M, and Bisgaier CL (1997). Cerebral lipid deposition in aged apolipoprotein E-deficient mice. Am J Pathol 151:1371-1377. 